\title{
How do clinicians choose antidepressants?
}

\author{
${ }^{\star}$ Rob Macpherson and Ed Robson
}

\begin{abstract}
A survey of the prescribing practice of a group of psychiatists working in a Bristol NHS frust found that their preferred choice of antidepressants was surprisingly similar, but reported doses of antidepressants often fell below generally accepted minimum levels. Clinicians used mainly nower antidepressants rather than tricyclics. The cholce of antidepressant was based on side effect proflie, overdose danger, training and personal experience of ellicacy. Cost and drug company advertising had titte offect on cholce. Dimiculties in involving depressed patients in treatment decisions are discuseed.
\end{abstract}

Research suggests no difference in efficacy between tricyclic and related antidepressant drugs. The British National Formulary (1993) lists 21 different antidepressants. Reviews of antidepressant treatment suggest that choice of antidepressant should be made on the grounds of previous drug exposure and side effect profiles of different drugs.

At present there are no clinical guidelines to indicate which antidepressant should be prescribed in particular clinical situations, and no evidence to suggest differences in subgroups of depressives in their response to antidepressants. Study of the rate of fatality in overdose has led Beaumont (1989) to advocate limiting the use of the older tricyclic drugs. Clinical experience sug gests that psychiatrists adopt a varied approach to treatment, and it has been argued (Joyce \& Paykel, 1989) that treatment with antidepressants is often inappropriate or inadequate, or both.

This study describes the antidepressant prescribing practice of a group of Bristol psychiatrists, and examines the reasons given by clinicians for their choice of antidepressant, and their attitudes to involving patients in choosing between alternative treatments.

\section{The study}

The instrument used was a 13-item postal questionnaire. It was sent twice to increase the response rate, with a two month interval, to all Southmead Trust doctors who work permanently in psychiatry. This included consultants, senior registrars, clinical assistants and postmembership registrars. Trainees without membership were not included, as it was felt that they may be a different group, comprising many GP trainees. The questionnaire asked about current antidepressant prescribing practice, and for the clinicians to describe their first line and second line antidepressants, and usual doses prescribed. It asked about the rationale for choosing particular antidepressants, whether seven specific factors had influenced choice, and for the clinicians to rank the three factors most influencing their decision. Attitudes to discussing treatment options with patients and to involving patients in treatment decisions were sought.

\section{Findings}

Of the 27 questionnaires sent out, 22 were returned, a response rate of $81.5 \%$. The respondents included seven consultant psychiatrists seven post-membership senior registrars/ registrars and eight clinical assistants. There were nine female and 13 male respondents. The mean frequency of initiating a course of antidepressants was 2.12 per week per professional. Two psychotherapists reported never prescribing antidepressants and have been excluded from parts of the analysis. Of the 20 prescribing respondents, 15 reported that lofepramine was their first-line antidepressant, others reporting prothiaden (3), doxepin (1) and amitriptyline (1). Second-line drugs included fluoxetine (6), trazodone (3), paroxetine (3), prothiaden (3), clomipramine (2), amitriptyline (2) and doxepin (1). The most commonly reported dose regime was lofepramine $70-210 \mathrm{mg}$, four respondents prescribing dally doses up to $280 \mathrm{mg}$. The usual daily doses of other drugs varied widely, mean maximal daily doses equating to amitriptyline $135 \mathrm{mg}$ (comparative dosage data from Bazire, 1993).

On the reasons for choosing a particular antidepressant, 11 of the 20 respondents reported that seeing the benefits of prescribing certain 
Table 1. Factors affecting antidepressant prescribing practice

\begin{tabular}{lll}
\hline & $\begin{array}{l}\text { Proportion stating } \\
\text { foctor affected } \\
\text { prescribing }\end{array}$ & $\begin{array}{l}\text { Factors 'influence } \\
\text { score' }\end{array}$ \\
\hline $\begin{array}{l}\text { Observing trends in } \\
\text { psychiatric practice }\end{array}$ & $16 / 20$ & 8 \\
$\begin{array}{l}\text { Training with clinicians } \\
\text { who have established } \\
\text { practice }\end{array}$ & $15 / 20$ & 17 \\
$\begin{array}{l}\text { Drug company advertising } \\
\begin{array}{l}\text { Differing side effect } \\
\text { profiles of anti-depressants }\end{array}\end{array}$ & $5 / 20$ & 1 \\
$\begin{array}{l}\text { Cost } \\
\begin{array}{l}\text { Overdose danger } \\
\text { Adverse personal experience } \\
\text { using certain drugs }\end{array}\end{array}$ & $14 / 20$ & 41 \\
\hline
\end{tabular}

drugs, while finding others ineffective, had been important. Most respondents were influenced by the seven specified factors, with the exception of cost and drug company advertising (see Table 1). Their ranking of the first, second and third most important factors was converted to scores of 3 , 2 and 1 respectively. This led to a cumulative 'influence score' for each of the seven factors. The highest scoring factor was the differing side effect profiles of antidepressants, followed by the danger of antidepressants in overdose, and adverse personal experience of using certain drugs. Other factors were considered less important, drug company advertising considered one of the three most important factors by only one respondent.

Discussing treatment options with patients presenting with depression (i.e. drug treatment, ECT or psychotherapy) was regarded positively by 19 of 22 respondents. However, the idea of discussing the choice of antidepressant drugs, based on facts about them, was less popular, 12 of 22 respondents being in favour.

\section{Comment}

This study surveyed the practice of a group of 22 psychiatrists regarding their treatment of depression. The response rate was reasonable for a postal questionnaire but refers purely to practice in a single, urban mental health trust. It is hard to know how representative this is. The reported rate of prescribing antidepressants indicates that each professional was responsible for initiating over 100 treatment courses per year.
Interestingly, these clinicians prescribed mainly the newer, more costly drugs. Cost and drug company advertising were considered relatively unimportant in determining choice of antidepressant. The cost of prescribing different antidepressants varies by up to one hundred times (Eccleston, 1993), and it seems unlikely that psychiatrists will remain unconcerned by such factors, given the current political climate and that $2.5 \%$ of the total NHS budget is spent on antidepressants (Slater, 1992). If doctors are influenced so little by advertising, it would be difficult to understand the amount drug companies spend on it.

These professionals varied in the extent they reported involving patients in decisions about treatment. Respondents were in favour of discussing the differing forms of treatment but less so involving patients in deciding the choice of antidepressant. Worrall (1989) advocates a formal model 'clinical decision analysis' for such communication with patients. Given widely differing practices, some considered inadequate by leading professional groups, it may be difficult to find a meaningful and consistent way of communicating such information to patients.

Reports of preferred antidepressant drug and dose varied. Fifteen professionals chose lofepramine as first-line treatment and of these seven reported the same dose range. Given the number of antidepressants available, the prescribing pattern found was remarkably uniform. In over half, the usual upper limits of doses fell below amitriptyline $150 \mathrm{mg}$ per day or equivalent - the dose recommended as the 
minimum effective for treatment. The prescribing practices of senior and junior psychiatrists were similar, and it is suggested that undertreatment of depressed patients may be occurring even by experienced psychiatrists. Alternatively, these psychiatrists may have found lower doses to be as effective in their clinical practice.

Over half of the respondents spontaneously volunteered that personal experience of efficacy had been a determining factor in the choice of antidepressant, often citing experience of having used ineffective drugs. By contrast, the psychiatric literature suggests no difference in efficacy between major antidepressants. 'Modelling' of the prescribing behaviour of senior training psychiatrists also influences practice, as does observing trends in the psychiatric literature, in particular the overdose toxicity of drugs.

This study has demonstrated variety in psychiatrists' prescribing of antidepressants. Choice appears to be based on many factors, perhaps reflecting the experiences and personalities of the clinicians as much as scientific evaluation. Despite encouragement in the literature for a more uniform approach to treating depression, it seems that the process remains an individual one based on the relationship between doctor and patient in which antidepressants are only one of a number of tools available. This area of psychiatric treatment remains as much an art as a science.

\section{Acknowledgement}

The authors are grateful to Dr I. E. Babiker for his helpful comments in preparing this manuscript, and to Elaine Cordey for producing it.

\section{References}

BAzIRE, S. (1993) Psychotropic Drug Directory. Quady Publishing.

BEAUMONT, G. (1989) The toxicity of antidepressants. British Journal of Psychiatry. 164, 454-458.

ECCleston, D. (1993) The economic evaluation of antidepressant drug therapy. British Journal of Psychiatry. 163, (Supplement 20), 5-6.

JOYCE, P.R. \& PAYKel, E.S. (1989) Predictors of drug response in depression. Archives of General Psychiatry. 46, 89-99.

SLATER, M. (1992) The economic evaluation of antidepressant therapy. Psychiatric Bulletin, 16, 566.

WORRALL, E.P. (1989) Consent to treatment and clinical decision analysis. Psychiatric Bulletin, 13, 79-81.

*Rob Macpherson, Sentor Registrar in Psychiatry, Rehabilitation Unit, Coney Hill Hospital, Gloucester GLA 7QJ; and Ed Robson, Senior Registrar in Psychiatry. The Burden Neurological Hospital, Stapleton, Bristol BS16 19T

*Correspondence 